\title{
Do Parental Attitudes Toward and Expectations for Their Children's Education and Future Jobs Matter for Their Children's School Achievement?
}

\author{
Cheng Yong Tan \\ The University of Hong Kong
}

The traditional discourse in the scholarship on cultural capital theory has focused on how exclusive participation in elite status culture by students from higher socioeconomic status families benefits their learning in schools, the effects of which are most evident in linguistic subject areas such as reading achievement. However, some scholars have argued that cultural capital is not restricted to elite status culture but could include parental familiarity with school evaluation standards and job market requirements, and that the effects could transcend languages to include performance domains with more objective evaluation and that are susceptible to school influences (e.g., mathematics and science). The present study systematically examines this position using data involving 96,591 15-year-old students from 3,602 schools in eight countries who participated in the Programme for International Student Assessment 2012. Results of three-level hierarchical linear modelling showed positive relationships between seven cultural capital variables and student mathematics achievement. The cultural variables comprised home educational resources; parental educational attainment and occupational status; parental expectations of their children's educational attainment, future career in mathematics, and school; and parental valuing of mathematics. In particular, the three parental expectations variables had substantively larger effect sizes on student achievement than the other cultural capital variables. The results demonstrated that parental familiarity with school evaluation standards and future job requirements, especially as measured by parental expectations, may constitute cultural capital that privilege student mathematics achievement in schools.

KEYWORDS: cultural capital, evaluative standards job markets, mathematics achievement

\section{Introduction}

Research evidence has consistently shown that children from higher socioeconomic status (SES) families have higher levels of school achievement (Sirin, 2005). Many scholars studying social reproduction have employed the conceptual heuristics of family capital to explain how higher SES parents pass on different types of advantages to benefit their children's learning (Tan, 2017). These advantages emanate from economic and non-economic resources such as cultural capital (Bourdieu, 1986).

According to Bourdieu (1986), cultural capital is arbitrarily sanctioned by schools, reinforced by school gatekeepers, and transmitted by higher SES parents to their children to perpetuate their social advantage. There are three forms of cultural capital - objectified, institutionalized, and embodied (Bourdieu, 1986). Objectified cultural capital refers to home educational and cultural resources that enable students to learn the dispositions, values, perceptions, knowledge, and skills that schools value. Next, institutionalized cultural capital is formed when cultural capital is publicly recognized as a marker of social distinction (e.g., via educational credentials). Lastly, embodied cultural capital refers to parental and student values and attitudes propitious to learning, tastes and preferences for academic pursuits, and 
DOI: $10.1002 /$ berj.3303

mastery of academic competencies and skills. These characteristics are emphasized in the formal school system (Bourdieu, 1986).

Many researchers reported a positive relationship between elite status culture, a manifestation of cultural capital (as exemplified by student highbrow cultural appreciation, tastes, and participation) and student performance (DiMaggio, 1982; Hvistendahl \& Roe, 2004; Mudiappa \& Kluczniok, 2015). However, some studies found that the influence of elite status culture was weaker than that of parental knowledge of the demands of modern, complex education systems and job markets, another manifestation of cultural capital in some educational contexts (De Graaf, De Graaf, \& Kraaykamp, 2000; Jaeger, 2009; Lareau \& Weininger, 2003; Prieu \& Savage, 2013; Sullivan, 2001). Additionally, there is some tentative evidence that cultural capital may benefit student learning in some subject areas (e.g., reading) more than others (e.g., mathematics and science) - see for example, Hvistendahl \& Roe (2004). These two findings are of concern given the importance of mathematics and science in many science, technology, engineering, and mathematics (STEM) jobs.

Deprivation of mathematical and science competencies and skills may limit student job opportunities in the modern economy.

The present study takes cognizance of the potential for students with mathematics and science competencies to experience upward social mobility, and therefore investigates if students with more cultural capital pertaining to parent familiarity with school evaluation standards and knowledge about what is valued in job markets have higher levels of mathematics achievement. The independent variables examined comprise all three forms of cultural capital. These variables include, but are not limited to, parental attitudes and expectations on mathematics learning, schooling, and future jobs, constituting variables which are relatively less explored indicators of embodied cultural capital (Jaeger, 2009).

\section{Cultural capital as familiarity with school evaluation standards and job markets}

Higher SES parents have a better appreciation and understanding of the expectations of schools and job markets constituting the logics of the field (Bourdieu, 2005). Therefore, they may provide their children with myriad forms of cultural capital and imbue them with the requisite habitus (Bourdieu, 1986). Habitus refers to a system of dispositions that influence parents and children's development of perceptions, appreciations, and practices (Bourdieu, 1990). This mobilization of resources is done to maximally promote the academic and career success of their children.

Traditionally, cultural capital researchers have focused on examining the effects of elite status culture on student achievement (e.g., DiMaggio, 1982). Elite status culture is exemplified by children's access to cultural resources at home and cultural participation. Home cultural resources comprise access to classical literature works, poetry books, and art works at home (Chiu \& McBride-Chang, 2010; Hvistendahl \& Roe, 2004). Cultural participation includes student participation in extracurricular activities, and parent and children's visits to venues such as museums, libraries, bookstores, zoos, farms, historical sites, art galleries, theatres, opera and ballet performances, and musical concerts (Mudiappa \& Kluczniok, 2015). However, other scholars question the relevance of elite status culture in different societies, particularly meritocracies in modern societies, and assert that parent familiarity with evaluation standards in the education system and knowledge about what is valued in job markets may be more salient in these societies (De Graaf et al, 2000; Jaeger, 2009; Lareau \& Weininger, 2003; Prieu \& Savage, 2013; Sullivan, 2001). Indeed, Prieur and Savage (2013) argue for the need to update our understanding of what constitutes relevant cultural capital, beyond elite status culture, that commands symbolic value to be in tandem with the pace of socio-technological transformations characterizing contemporary societies. Educational evaluation standards and knowledge about job markets here refer to the 
DOI: $10.1002 /$ berj.3303

knowledge, competencies, and skills that are needed for students to excel in the education system and in lucrative STEM careers (Crosnoe \& Muller, 2014; Gauld \& Hukins, 1980; Ma, 2009). For example, according to Bourdieu and Passeron (1979), higher SES parents have 'the eye for a good investment which enables one to get the best return on inherited cultural capital in the scholastic market or on scholastic capital in the labour market' (p. 82). This group of scholars reasons that cultural capital must command value in the educational field, so this academic and strategic knowledge, as opposed to elite status culture, are more legitimate and relevant markers of social distinction in meritocratic societies (Prieur \& Savage, 2013). This knowledge pertains to, among other attributes, parental familiarity with educational processes and systems (Vryonides, 2007), and parental involvement and choice in meeting school evaluative standards (Reay, 2004). Akin to elite status culture, this knowledge is subject to monopolization by the dominant social classes in society (e.g., higher SES parent), can be transmitted from parents to their children, and will yield profits to its bearers (Lareau \& Weininger, 2003). However unlike elite status culture, it may privilege student achievement in subjects with more objective evaluation standards such as mathematics and science (DiMaggio, 1982).

A review of the literature indicates that most researchers adopting this 'familiarity', as opposed to elite status culture, perspective do not examine the effects of all three forms of cultural capital on student achievement (Hvistendahl \& Roe, 2004). For example, Hvistendahl and Roe's (2004) study of eighth grader minority students in Norway examined only objectified (books at home) and embodied (parent-child discussions on children's school achievements and parent-child interactions) cultural capital. Without a systematic examination of the different forms of cultural capital, we are not able to know how cultural capital may mediate the effects of social origins on student achievement. In particular, there are relatively fewer studies conceptualizing cultural capital as parental attitudes and expectations pertaining to learning, schooling, and future job opportunities (e.g. Jaeger, 2009).

\section{Cultural capital effects on mathematics achievement}

The present study examines the relationship between cultural capital and student mathematics achievement (as opposed to other subject domains such as reading).

Mathematics achievement is the dependent variable of interest considering the importance of mathematical competencies and skills in many higher education courses and careers in STEM (Ma, 2009). The lack of student interest in and shortage of students pursuing higher education and careers in STEM has also occupied the policy agenda of many governments (Archer, Dawson, DeWitt, Seakins, \& Wong, 2015; Xie, Fang, \& Shauman, 2015). It is therefore imperative to know if there is social reproduction in mathematics achievement that contributes to the current conundrum in STEM participation.

Indeed, the evidence is mixed as to whether cultural capital benefits students in their mathematics (and science) achievement. For example, Hvistendahl and Roe's (2004) study of eighth grader minority students in Norway found that student highbrow cultural possessions, parent-child discussions on children's school achievements, parent-child interactions correlated with their reading and science (but not mathematics) achievement. However, they also found that the number of books at home did not correlate with student mathematics or science achievement. Furthermore, student highbrow cultural participation did not correlate with their academic achievement in mathematics, science, or reading.

Could cultural capital benefit student mathematics and science achievement? On the one hand, students need to acquire mathematics competencies and skills such as logical, deductive, and inductive thinking skills, and creative and critical problem-solving to solve higher-order mathematics questions. Students from higher SES families have more 
DOI: $10.1002 /$ berj.3303

opportunities to be exposed to these abstract modes of thinking (embodied cultural capital) than their less privileged peers (Acosta \& Hsu, 2014). At the same time, higher SES parents may also be more cognizant of the importance of these abstract attributes (embodied cultural capital) in STEM careers (Archer et al, 2015; Aschbacher, Ing, \& Tsai, 2014), and therefore they are more likely to equip their children with these requisite attributes. These arguments suggest that students from higher SES families may be able to benefit from their cultural capital in their mathematics achievement.

On the other hand, it can be argued that mathematics assessment is more objective than reading assessment, and therefore less susceptible to the influence of familial cultural capital. For example, reading achievement may be more affected by subjective and stylistic variables than achievement in a subject such as mathematics. Parents also do not teach mathematics as naturally or as competently as they do language skills in daily family interactions (Castro et al, 2015). At the same time, mathematics learning may require access to mathematics learning manipulatives or specialized software which are less available to parents than reading resources such as books, but which are more easily found in schools than in households. However, these school learning resources may be more easily available in developed than developing countries where there may be greater investment in the education system, and where principals and teachers are more equipped to use these resources to enhance student learning (Hanushek \& Woessmann, 2017; Heyneman \& Loxley, 1983; Little $\&$ Rolleston, 2014). Consequently, the quality of home parental involvement may be less important than that of mathematics teaching and learning in schools, especially in more developed countries (Osborne, Simon, \& Collins, 2003).

Therefore, higher levels of cultural capital may benefit achievement more in reading than in mathematics or science (Hvistendahl \& Roe, 2004).

In the sections that follow, the contribution of home educational resources (objectified cultural capital); parental education (institutionalized cultural capital); parental occupational status, parental academic expectations of children and schools, and parental perceived mathematics importance and career expectations (embodied cultural capital) to student mathematics achievement will be discussed.

\section{Home educational resources}

First, higher SES parents may have a better understanding of what their children are expected to learn in schools, and they invest in their children by providing the latter with educational resources (as contrasted with highbrow cultural resources) to support their learning at home. These resources include books, learning technology such as computers, and conducive studying environments. Indeed, according to Bourdieu (2000), parental interest in securing positive outcomes for their children manifests early on as a form of 'investment in the domestic space' (p. 166). There is empirical evidence that children who have access to more quality home educational resources have higher levels of academic achievement (Claro, Cabello, Martín, \& Nussbaum, 2015; Iruka, Dotterer, \& Pungello, 2014). For example, Claro and colleagues' (2015) study of eighth graders in Chile found that home availability of study desks, study areas, computers, educational software, and Internet connection was positively associated with their mathematics and reading achievement. The present study will examine the relationship between home educational resources and student mathematics achievement. It is expected that the availability of home educational resources will be positively related to student achievement.

\section{Parental education and occupational status}

Some scholars perceive schools as sites of symbolic violence which privilege pedagogic actions and scientific capital (Bourdieu, 1993; Bourdieu \& Passeron, 1977). For 
DOI: $10.1002 /$ berj.3303

example, the formal education system favours academic over vocational learning, critical thinking over rote learning, and assertiveness over passivity (Gauld \& Hukins, 1980).

Obviously, more highly educated parents, having successfully navigated the system, are more acquainted with these pedagogic actions and scientific capital. They may also have a better understanding of school course requirements. For example, Crosnoe and Muller's (2014) study of high school students showed that students with college-educated parents benefited from their knowledge about the weight distribution of grades, core courses, and electives in the transition to college.

The scientific capital is developed further in individuals holding higher-paying STEM jobs requiring mathematical or scientific competencies (Ma, 2009). Parents with higher occupational status are also more updated with the types of dispositions, competencies, and skills that employers look for in new hires (Crosnoe \& Muller, 2014). Therefore, higher SES parents (more educated, higher occupational status) are better able to advise their children on their educational and career trajectories. In summary, parental education attainment and occupational status constitute cultural capital, signifying technical and 'social' competence that bestows prestige to their holders (Bourdieu, 1996).

Indeed, there is empirical evidence that more highly educated parents or parents with higher occupational status emphasize in their children language stimulation and behavioural regulation, employ positive parenting styles, provide cognitively stimulating home environments, and influence the development of children's educational aspirations (Dubow, Boxer, \& Huesmann, 2009; Iruka et al., 2014; Myberg \& Rosen, 2009; Sektnan, McClelland, Acock, \& Morrison, 2010; Zadeh, Farnia, \& Ungerleider, 2010). These practices contribute to children's academic achievement (Chiu and Khoo, 2005; Croll, 2008). For example, Chiu and Khoo's (2005) multinational study found that eighth grade students whose parents had higher levels of educational attainment and who had higher occupational status had higher levels of achievement. Croll's (2008) analysis of data from the British Household Panel Survey found that 15-year-old youths whose parents enjoyed higher occupational status were more occupationally ambitious, and had better educational and occupational outcomes in their early 20 s themselves.

The present study will examine the relationship between parental education and occupation status, and student mathematics achievement. It is expected that these parental independent variables will be positively related to student achievement.

\section{Parental expectations of children and schools}

Higher SES parents internalize a habitus that contributes to their academic and career success. This habitus is shaped by prior experiences in schools and at work, and it in turn influences their present practice and future expectations (Bourdieu, 2000). These expectations may pertain to their children's academic achievement and to their academic expectations of schools (Rimkute, Hirvonen, Tolvanen, Aunola, \& Nurmi, 2012). The habitus gives them the knowledge and confidence to have a good sense of what is reasonable and achievable for their children, and the role that schools can play to realize these expectations. The more accurate appraisal and expectations are communicated to their children (Archer et al, 2015; Boone \& van Houtte, 2013; Chen \& Gregory, 2010; Gniewosz \& Noack, 2012; Jacobs \& Harvey, 2005), as evident by Boone and van Houtte's (2013) study which reported that student perceptions of their educational choices were circumscribed by parent perceptions of what was deemed to be 'acceptable' educational alternatives. Higher SES children also have the financial wherewithal to pursue higher STEM education requiring longer periods of study (Ma, 2009). Therefore, they may be more motivated to realize their parents' expectations by first excelling in subjects such as mathematics and science which constitute the conceptual and computational foundation of many STEM courses of study (Ma, 2009). 
DOI: $10.1002 /$ berj.3303

Not surprisingly then, the seemingly 'subjective expectations' of parents predictably eventuate in 'objective probability' of their children's success (Bourdieu, 1990, p. 59). There is empirical evidence that parental expectations are positively associated with children's academic achievement (Chen \& Gregory, 2010; Jacobs \& Harvey, 2005; Rimkute et al., 2012). Chen and Gregory (2010) found that ninth grade students whose parents had higher expectations about their children's grades and attainment had higher grade point averages. Jacobs and Harvey (2005) reported in their study of Australian high school students that parental expectations of their children's education, and the length of time they had maintained those expectations were the strongest predictors of their children's educational attainment as compared to other variables such as their attitudes toward their children's school environments, their encouragement for and interest in their children's education, or their attitudes toward achievement.

Similarly, children from schools confronted with more demanding parents may have higher levels of academic achievement (Gordon \& Louis, 2009), especially in the neoliberal context of educational accountability (Ball, 2003; Lee, Walker, \& Chui, 2012). Higher SES parents may exert academic pressure on schools in many ways, including supporting their children's absence from classes to study for high-stake tests, exerting pressure on schools in cases of perceived injustice in assessment of their children's work, and appropriating special education policy provisions to benefit their children (Demerath, Lynch, Milner IV, Peters, \& Davidson, 2010). Weininger and Lareau (2003) illustrated that higher SES parents could also exert academic pressure on schools in parent-teacher conferences, displaying behaviours such as criticizing teachers, advocating for their children, and demanding special pedagogical provisions for their children. High parent academic expectations may motivate principals to provide strong instructional leadership (Ladd \& Fiske, 2003; Lee et al., 2012), thereby promoting a positive school culture that eventuates in higher levels of student achievement.

The present study will examine the relationship between parental expectations of their children and school, and student mathematics achievement. It is expected that parental expectations will be positively related to student achievement.

\section{Parental perceived mathematics importance and career expectations}

Higher SES parents are more cognizant of the logics of the field because of their familiarity with the education system or job markets (Crosnoe \& Muller, 2014). In the context of the knowledge-based economy, there are exciting and lucrative STEM job opportunities privileging individuals with strong scientific and mathematical knowledge, competencies, and skills (Ma, 2009). Therefore, these parents have a greater appreciation of the instrumental value of subjects such as mathematics in maximizing their children's economic interest. Indeed, Bourdieu (1994, p. 90) assert that 'most actions are objectively economic' even if they do not appear to be 'subjectively economic'. Given parents' understanding of the importance of mathematics, they may share with their children their appreciation of the strategic value of mathematics and science mastery as a prerequisite to many tertiary courses of study, and for embarking on STEM careers ultimately (AdamutiTrache \& Andres, 2008; Archer et al., 2015; Boone \& van Houtte, 2013; Chen \& Gregory, 2010; Gniewosz \& Noack, 2012; Jacobs \& Harvey, 2005). For example, Gniewosz and Noack (2012) reported that parent perceptions of the attainment, utility, and intrinsic value of mathematics education positively predicted their children's valuing of the subject. In turn, higher SES children may have higher levels of school achievement in mathematics because they have extra resources to follow up on their learning after school (Aschbacher et al, 2013), and they are ready and able to invest their energies and time to pursue STEM courses requiring many years of study (Calabrese Barton et al., 2013). There is empirical evidence of the effects of parents valuing mathematics or science on children's academic achievement 
DOI: $10.1002 /$ berj.3303

(Acosta \& Hsu, 2014; Perera, 2014). For example, Acosta and Hsu's (2014) study of eighth grade students in Hong Kong found that parent valuing of science was correlated with higher student science achievement both directly and indirectly via student valuing of and motivation in learning science. Perera's (2014) analysis of PISA data reported that 15-yearold students whose parents valued science had higher levels of science achievement.

\section{The present study}

The present study will examine the relationship between cultural capital variables related to parental familiarity with school evaluation standards and job market requirements, and student mathematics achievement. These variables comprise home educational resources, parental educational attainment and occupation status, but also more importantly, parental expectations of their children's education, career, and school, and parental perceived importance of learning mathematics. It is expected that all the parental variables will be positively related to student achievement, after controlling for four variables to mitigate against threats to validity, namely student sex, school enrolment, and country state of economic development and sociocultural values. First, student sex is included as there is some evidence that boys continue to outperform girls in mathematics achievement although the gap is gradually closing (Krapp \& Prenzel, 2011). Second, students in larger schools may have access to more quality teachers and educational resources which benefit their learning but teachers may also struggle to cater to the learning needs of the substantial number of students in these large schools (Hattie, 2009). Third, the analysis will include a variable measuring whether a country is an Organisation for Economic Cooperation and Development (OECD) country, as more economically developed countries may invest more in developing teacher quality (Baker, Goesling, \& LeTendre, 2002) which benefits student learning. The Heynemon-Loxley Effect also suggests a larger family effect in developed as opposed to developing countries (Baker et al, 2002). Lastly, the analysis will include another variable indicating whether a country has a Confucian heritage culture $(\mathrm{CHC})$. This variable is important because international studies have shown the CHCs have higher levels of student achievement attributed to the sociocultural premium on education (Han \& Makino, 2013).

\section{Method \\ Participants}

The study used data from PISA 2012 (OECD, 2013). PISA 2012 measured 15-yearold students' proficiency in applying their knowledge and skills learned in mathematics, science, and reading to authentic problems. It also collected data on student educational experiences and attitudes. These students were selected to represent the complete population of 15-year-old students who were attending public or private schools in grade 7 or higher in the participating countries.

According to Young, Weckman, and Holland (2011), it is not meaningful for data imputation if there is more than $15 \%$ of missing values in the data because there is little information on the pattern of missing values. A country-by-country examination of missing values for the key variables to be examined in the present study indicated that only eight countries (Chile, Hong Kong, Croatia, Hungary, Italy, Korea, Macau, and Mexico), out of 11 countries with student, parent, and principal data in PISA 2012, had less than this proportion of missing values for the key variables. Therefore, only data from these countries, comprising 96,591 students and their parents from 3,602 schools, were included in the present study. ${ }^{1}$

\footnotetext{
${ }^{1}$ Data from three other countries (namely Belgium, Germany, and Portugal) were excluded because the percentage of missing values for the variables was deemed to be unacceptably high, exceeding recommended
} 
DOI: $10.1002 /$ berj.3303

These countries had relatively higher levels of student mathematics and science achievement in international assessments, and relatively low levels of students who had not acquired basic mathematics and science skills (OECD, 2015). Most of them (except Mexico) also had very high levels of secondary school enrolment rates (> 90\%) and were upper-middle to highincome countries (OECD, 2015).

\section{Measures}

Data on the following variables from the PISA 2012 dataset were used in the analysis.

Student mathematics achievement (Math) was the focal achievement variable measured in PISA 2012. Students were not administered the complete set of test items by design, and therefore each item had missing responses. This made it impossible to estimate achievement scores for each student. To overcome this limitation, PISA 2012 aggregated the results of individual students to produce scores for groups of students. For each student then, the estimated distribution of mathematics scores of students similar to him or her in terms of responses to the assessment and background items was represented by a set of five 'plausible values' (PVs; OECD, 2014). However, there is an inherent measurement error because these PV scores were estimated. To account for the measurement error, the present analysis used HLM7.01 (Raudenbush, Bryk, Cheong, Congdon, \& du Tolt, 2011) which first estimated parameters for each of the five PVs before averaging the estimates in the HLM analysis (to be described later). HLM7.01 then combined the average of the sampling error from the five PVs with the variance between them multiplied by a factor related to the number of PVs.

The access to educational resources (HomeEdRes) in student homes (objectified cultural capital) was summarized by a Rasch measure in PISA 2012 that was calibrated using student responses (Yes or $\mathrm{No}$ ) on the presence of study desk, quiet place to study, computer for school work, educational software, school-related books, reference books, and dictionary at home $(0.86 \%$ missing $)$.

Parents also responded to items asking about their highest level of schooling completed corresponding to different levels of educational attainment relevant to their countries. The responses were then recoded into values ranging from 0 to 3 to enable meaningful comparisons across countries, with $0=$ None, $1=$ Completed general upper secondary and/or non-tertiary post-secondary education, $2=$ Completed vocational tertiary education, 3 = Completed theoretically oriented tertiary and postgraduate education. Parent institutionalized cultural capital (ParentEd) was measured by the higher education level of either parent or the only available parent (11.23\% missing).

Embodied cultural capital was measured by five variables.

- $\quad$ First, PISA 2012 coded parent responses to two open-ended items on their main job (job title and description) into four-digit ISCO codes and mapped them to the international socioeconomic index of occupational status (Ganzeboom, 2010). Parental occupational status (OccpStatus) was measured by the higher occupational status of either father or mother, or to the only available parent (10.29\% missing).

- $\quad$ PISA 2012 computed a Rasch measure of parental perceived importance of mathematics (MathImport; 7.98\% missing)) using parent responses to four items on the extent of their agreement on the importance of mathematics for

\footnotetext{
thresholds (e.g., 15\%; see Young et al, 2011). The decision to exclude these three countries means that we have data from only a few countries (in this case, eight) to be analysed, thereby compromising transnational generalisability of the results. However, this decision hedges against the risks from analysing potentially inaccurate data from the other three countries, even with multiple imputations. Fundamentally, it is not meaningful to impute values if there are too many missing values in the data (Young, et al, 2011).
} 
DOI: $10.1002 /$ berj.3303

work $(1=$ Strongly disagree, $2=$ Disagree, $3=$ Agree, $4=$ Strongly agree $)$. These items pertained to the need to have good mathematics knowledge and skills to get good jobs and perceived employer appreciation of mathematics knowledge and skills in their employees.

- $\quad$ Parental educational expectations (PaEduExp) of their children were measured by their responses (Yes or No) to an item on whether they expected their children to complete a theoretically oriented tertiary or postgraduate education (59.80\% Yes, $33.40 \%$ No, $6.74 \%$ missing).

- $\quad$ Parental mathematics career expectations (PaExpCa) of their child were measured by their responses (Yes or No) to an item on whether they expected their child to enter a mathematics-related career $(49.00 \% \mathrm{Yes}, 42.10 \% \mathrm{No}$, $8.90 \%$ missing).

- $\quad$ Parental expectations of schools (Pressure; $4.18 \%$ missing) were measured by school principal responses to an item on the extent of pressure parents exerted on schools to achieve high academic standards $(1=$ Pressure was largely absent, 2 = Only a minority of parents exerted pressure, $3=$ Constant pressure from many parents).

Four variables were included as controls in the HLM analysis.

- $\quad$ A dummy variable measuring student sex (Sex) was coded as 0 for female $(50.1 \%)$ and 1 for male $(49.9 \%)$ students.

- $\quad$ SchSize (3.97\% missing) measured the total number of students enrolled in the school as reported by principals.

- $\quad$ Countries' economic development (OECD) was measured by a dummy variable coded as 1 for OECD countries ( 5 countries) and 0 otherwise ( 3 countries).

- $\quad$ Countries' Confucian heritage culture (CHC) was measured by a dummy variable coded as 1 (3 countries) for $\mathrm{CHC}$ and 0 otherwise (5 countries).

The descriptive statistics of the variables are summarized in Table 1. 
Table 1. Summary of means and standard deviations for variables.

\begin{tabular}{lcc}
\hline Variables & $M(S D)$ & \%Missing \\
\hline MathPV1 $^{2}$ & $470.59(97.50)$ & 0 \\
MathPV2 & $470.59(97.55)$ & 0 \\
MathPV3 & $470.58(97.62)$ & 0 \\
MathPV4 & $470.57(97.54)$ & 0 \\
MathPV5 & $470.61(97.70)$ & 0 \\
HomeEdRes & $-0.37(1.07)$ & 0.86 \\
ParentEd & $2.40(1.78)$ & 11.23 \\
OccpStatus & $44.16(20.89)$ & 10.29 \\
MathImport & $0.05(0.97)$ & 7.98 \\
SchSize & $834.96(649.04)$ & 3.97 \\
Pressure & $1.82(0.68)$ & 4.18 \\
\hline
\end{tabular}

\section{Procedure}

PISA 2012 used a two-stage stratified sampling design, with schools first selected from a national sampling frame of schools with probabilities proportional to size, and students then selected from within each selected school (Liou \& Hung, 2015). PISA 2012 was sponsored internationally by the OECD and coordinated and administered internationally by the PISA international consortium, led by the Australian Council for Educational Research. All participating economies followed standardized procedures outlined in the technical standards and manuals provided.

\section{Analytical strategy}

Missing values imputation and HLM were used in the analysis.

\section{Multiple imputations}

Missing values may compromise estimation efficiency and produce biased results. Therefore, the Markov chain Monte Carlo multiple imputation was employed to address the methodological challenge arising from missing values in the data. This multiple imputation procedure is a generally more effective method of data imputation as compared to other missing values treatment procedures, and especially useful for large samples or in data with higher percentages of missing values (Cheema, 2014). The multiple imputation procedure imputed missing values five times, thereby producing multiple complete data sets. In the

\footnotetext{
${ }^{2}$ The use of PVs yields unbiased estimates of the population mean and standard deviation. In particular, simulation studies showed that the PV methodology was able to yield unbiased estimates of the population standard deviation which alternative estimation techniques such as weighted maximum likelihood estimates, maximum likelihood estimates, and expected A-posteriori estimates could not (Wu, 2005). Therefore, both the means and standard deviations of the five MathPV's are expected to be very similar in value.
} 
DOI: $10.1002 /$ berj.3303

present study, the pooled parameter estimates (across the five imputed datasets) are analysed. The standard errors of the estimates are unbiased when this procedure is used.

\section{HLM}

Three-level (student, school, and country) fixed effect HLM with full maximum likelihood estimation (Raudenbush \& Bryk, 2002) was next performed to examine the relationship between cultural capital and student achievement using HLM7.01. HLM was employed because of its advanced computational capability to handle the complex nested nature of the PISA data (e.g., students belonging to different schools), test for mean differences in dependent variables (student mathematics achievement), incorporate both continuous (e.g., MathImport) and categorical variables (e.g., Sex), account for the different sizes of units, and compute the proportion of explained variance at different levels (student and school) (Dedrick et al., 2009).

The independent variables were rescaled by subtracting the sample grand mean from the respective raw scores for ease of interpretation. After the rescaling, each HLM parameter represents the 'effect' of the respective variable for a student with values on the other variables that are each equal to the grand mean for the respective variable. Three nested models were examined as follows:

- Model 1 - baseline with no predictors;

- Model 2 - random intercepts model with control variables (Sex, SchSize, OECD, and $\mathrm{CHC}$ ) added; and

- Model 3 - random intercepts model with cultural capital (HomeEdRes, ParentEd, OccpStatus, PaEduExp, Pressure, MathImport, and PaExpCa) and control variables added.

\section{Results}

Results from Model 1 showed that the variance in student mathematics achievement occurred at various levels - student (41.01\%), school (34.61\%), and country (24.38\%). This indicated that differences in student achievement were not attributed solely to individual attributes (within-student), but also to school and country factors. These results justified the use of HLM in the analysis.

Results from Model 2 showed that boys had higher levels of mathematics achievement than girl $(\pi=21.60, p<.001)$. Additionally, students attending schools with more students (SchSize, $\beta=0.03, p<.001)$ and from CHCs $(\mathrm{CHC}, \gamma=76.99, p<.05)$ outperformed peers in schools with fewer students and from non-CHCs respectively. There was no difference in the mathematics achievement of students from OECD and non-OECD countries $(\mathrm{OECD}, \gamma=-7.16, p=0.48)$.

Results from Model 3 showed similar patterns of relationships between these control variables and student mathematics achievement. After controlling for these variables, the results showed positive relationships between the cultural capital variables and student achievement. More specifically, (a) students with more home educational resources (HomeEdRes, $\pi=3.57$ ); (b) students with parents who were more highly educated (ParentEd, $\pi=0.74$ ) and who had higher occupational status (OccpStatus, $\pi=0.22$ ); (c) students whose parents had higher educational expectations of their children (PaEduExp, $\pi=23.93$ ), higher career expectations in mathematics of their children $(\mathrm{PaExpCa}, \pi=17.31)$, and higher academic expectations of their children's school (Pressure, $\beta=10.94$ ); and (d) students whose parents regarded mathematics as more important (MathImport, $\pi=1.15$ ), had higher levels of achievement at the .001 level. The cultural capital variables in Model 3 accounted for 5.03\% 
of the student achievement variance after controlling for Sex, SchSize, OECD, and CHC (when compared to Model 2). ${ }^{3}$

The grand mean centering employed enables us to compare effect sizes of the cultural capital variables. Among the diverse types of cultural capital, parental expectations appeared to have the strongest relationships with student achievement. More specifically, a student whose parents had higher educational expectations (one standard deviation above the average level) was more likely to score 23.93 points more than another whose parents had an average level of educational expectations, a relatively large difference given that the standard deviation of Math PVs was about 98 points (Table 1). Similarly, a student whose parents had higher mathematics career expectations (one standard deviation above the average level) was more likely to score 17.31 points more than another whose parents had an average level of mathematics career expectations. Even parental academic expectations of their children's school had a relatively large effect size - a student whose parents had higher academic expectations of the school (one standard deviation above the average level) was more likely to score 10.94 points more than another student with average parental school expectations.

In contrast, parental educational attainment and occupational status had the weakest relationships with student achievement. This is evident in that a student whose parents were more educated (one standard deviation above the average level) was more likely to score only 0.74 points more than another whose parents has an average level of educational attainment. Similarly, a student whose parents enjoyed higher occupational status (one standard deviation above the average level) was more likely to score only 0.22 points more than another whose parents had an average level of occupational status.

\footnotetext{
${ }^{3}$ The amount of variance explained was computed by comparing the remaining level 1 (student level) variance between Model 2 and 3, that is $(4,048.46-3,844.89) / 4,048.46 * 100 \%=5.03 \%$.
} 
DOI: $10.1002 /$ berj.3303

Table 2. Fixed effects estimates (top) and variance estimates (bottom) for models of the predictors of Mathematics achievement.

\begin{tabular}{|c|c|c|c|}
\hline Parameters & Model 1 & Model 2 & Model 3 \\
\hline \multicolumn{4}{|c|}{ Fixed effects } \\
\hline Intercept & $486.00 * * *(17.65)$ & $482.18 * * *(8.39)$ & $484.72 * * *(8.99)$ \\
\hline \multicolumn{4}{|l|}{ Level 1} \\
\hline Sex & & $21.60 * * *(0.53)$ & $20.11 * * *(0.50)$ \\
\hline HomeEdRes & & & $3.57 * * *(0.26)$ \\
\hline ParentEd & & & $0.74 * * *(0.17)$ \\
\hline OccpStatus & & & $0.22 * * *(0.01)$ \\
\hline PaEduExp & & & $23.93 * * *(0.60)$ \\
\hline MathImport & & & $1.15^{* * *(0.29)}$ \\
\hline $\mathrm{PaExpCa}$ & & & $17.31 * * *(0.59)$ \\
\hline \multicolumn{4}{|l|}{ Level 2} \\
\hline SchSize & & $0.03 * * *(0.00)$ & $0.02 * * *(0.00)$ \\
\hline Pressure & & & $10.94 * * *(1.33)$ \\
\hline \multicolumn{4}{|l|}{ Level 3} \\
\hline OECD & & $-7.16(19.62)$ & $-16.04(21.02)$ \\
\hline $\mathrm{CHC}$ & & $76.99 *(19.63)$ & $72.05 *(21.03)$ \\
\hline
\end{tabular}

Random parameters

$\begin{array}{lccc}\begin{array}{l}\text { Level 1 } \\ \text { intercept }\end{array} & 4,151.52 & 4,048.46 & 3,844.89 \\ \begin{array}{l}\text { Level } 2 \\ \text { intercept }\end{array} & 3,503.05^{* * *} & 3,277.57^{* * *} & 2,501.51^{* * *} \\ \begin{array}{l}\text { Level 3 } \\ \text { intercept }\end{array} & 2,468.30^{* * *} & 540.28^{* * *} & 629.39^{* * *} \\ \begin{array}{l}\text { \% Level 1 } \\ \text { variance } \\ \text { \% Level 2 } \\ \text { variance } \\ \% \text { Level 3 }\end{array} & 41.01 & 51.47 & \\ \text { variance } & 34.61 & 41.67 & 55.12 \\ & 24.38 & 6.87 & 35.86\end{array}$

Note: Standard errors in parentheses.

$* * * p<.001 . * * p<.01 . * p<.05$. 


\section{Discussion}

Overall results from the analysis provide support that all three forms of cultural capital (objectified, institutionalized, and embodied) contribute to student achievement, albeit to different degrees. The results underscore the argument that cultural capital need not be exclusively elite status culture, but could comprise parental familiarity with school evaluation standards and job market requirements. They also demonstrate that cultural capital can influence student learning in a subject domain such as mathematics.

In particular, the results indicate that parental expectations, whether they pertain to their children's educational attainment, their children's future mathematics-related career, or school academic emphasis are more important than parental achievements (as measured by their educational attainment and occupational status). These results are consistent with those reported in some studies (Dar \& Getz, 2007; Hauser, Tsai, \& Sewell, 1983). For example, Dar and Getz's (2007) study alluded to the importance of student expectations for a university education. They found that Israeli tertiary students did not mind studying less prestigious disciplines (e.g., education or humanities) as long as they could enter universities as compared to colleges. These results affirmed the importance of student educational expectations, and if these expectations are influenced by parental expectations (AdamutiTrache \& Andres, 2008; Archer et al, 2015; Boone \& van Houtte, 2013; Chen \& Gregory, 2010; Gniewosz \& Noack, 2012; Jacobs \& Harvey, 2005), they will therefore allude to the importance of parental expectations on student achievement. Indeed, status attainment models have long underscored the role of educational and career expectations on children's achievement (Hauser et al., 1983). The results on the importance of parental expectations are significant for mitigating the effects of social origins on student achievement because schools can influence parental expectations but they cannot change parental achievements, assuming that all parents could be persuaded to have higher expectations - a point that would be discussed shortly. For example, schools could engage parents more closely, foster parental involvement in their children's learning, and communicate the importance of raising parental expectations for student learning.

However, the results showing stronger relationships for parental expectations as compared to parental achievements may also occur because expectations as embodied cultural capital have merely mediated the effects of parental achievements and also home educational resources. These results highlight the relative importance of individual parental perspectives as compared to less subjective variables in the transmission of social privilege. The mediation hypothesis is not tested in the present study, but the plausibility may imply that it is premature to discount the role of social origins on student achievement. In a related vein, there is some evidence that the effects of expectations for their children's education from more highly educated parents are more consequential than those from less educated parents (Tan, 2015). Therefore, school efforts that concentrate on simply enhancing parental expectations of their children's learning without consideration of parental socioeconomic backgrounds may not necessarily eventuate in higher levels of student achievement.

One surprising finding is that parental perceptions of the importance of mathematics was not as strongly related to student achievement as parental expectations of their children and schools. Previous studies showed that parental expectations and perceived mathematics importance were significant predictors of student achievement (Acosta \& Hsu, 2014; Perera, 2014), so the results are not totally consistent with the literature. One plausible reason is that parental perceived importance of mathematics shapes their subsequent expectations, especially in areas related to mathematics. For example, parents may appreciate the importance of mastery in mathematics and science as a prerequisite to exploiting many exciting and potentially lucrative STEM job opportunities. Therefore, they expect their children to excel academically in schools so that they can then secure STEM jobs. These 
DOI: $10.1002 /$ berj.3303

higher levels of parental expectations would then predict higher levels of student mathematics achievement. However, another plausible reason is that there are other psychosocial variables that exert a more important influence on student achievement. These variables include student peer attitudes toward mathematics; student mathematics self-concept, motivation, and enjoyment; student fear of failure in mathematics; and perceptions of social impact of mathematics and of mathematics taught in school (Archer et al., 2015; Osborne et al., 2003).

\section{Conclusion}

The present study examines the relationships between different forms of cultural capital (objectified, embodied, and institutionalized) and mathematics achievement of 96,591 eighth grade students from 3,602 schools in eight countries. It presents the results of a robust test of the theory that parent familiarity with school evaluation standards and future occupational needs may benefit student learning in terms of their mathematics achievement by (a) using data from different respondents (parents, students, and principals) and from different countries; (b) including different forms of cultural capital (objectified, embodied, institutionalized); (c) controlling for extraneous influences (student sex, school size, country economic development, and sociocultural norms on learning); and (d) employing HLM to account for the unique structure of the data (students and parents 'nested' in schools). The cultural capital variables examined are children's access to home educational resources, parental educational attainment, parental occupational status, and more importantly, parental academic expectations of their children and schools, parental perceived importance of mathematics in future jobs, and parental mathematics career expectations of their children. These cultural capital variables relate more to parent familiarity with school evaluation standards and future occupational needs than to elite status culture.

These results contribute to the literature in three ways. First, they demonstrate that parent cultural capital as evidenced by their familiarity with evaluation standards and job market requirements, is a valid predictor of student mathematics achievement. Therefore, the study contributes to the debate on whether the conceptualization of cultural capital could include forms beyond elite status culture, and whether it could contribute to student achievement in subjects with objective (e.g., mathematics and science) as compared to diffused evaluation criteria (e.g., reading) (Hvistendahl \& Roe, 2004).

Second, the overall influence of the variables measuring the three forms of cultural capital on student achievement across the eight countries examined provide evidence for social reproduction in student mathematics. Given the importance of mathematics competence in many STEM occupations that offer better monetary and career prospects (Ma, 2009), the implications arising from the results of the present study cannot be understated.

Third, the results showing the relative importance of parental expectations (of their children's educational attainment and career trajectories, and of their children' school) as compared to other less 'malleable' cultural capital variables (e.g., parental education attainment and occupational status) on student achievement suggest that policymakers, school principals and teachers may be able to work toward boosting parents' confidence in their children's learning ability and raising parents' expectations of their children. This strategy helps in developing non-dominant cultural capital in lower SES families and promotes the development of 'resilient' children (De Graaf et al., 2000). This strategy may be efficacious if future studies could establish that parental expectations do not merely mediate effects of parental socioeconomic attributes (e.g., educational attainment or occupational status) on student achievement, but rather influence student achievement independently.

As with all studies, the present study suffers from some limitations. First, despite the considerable number of variables available in the PISA 2012 dataset, the cross-sectional design of the study precludes any definitive causal claims between cultural capital and 
DOI: $10.1002 /$ berj.3303

student achievement. The second limitation is that there were eleven countries with parentchild data to start with, but only eight of them were included in the analysis because of their more complete data. Therefore, the results reported in the present study should not be extrapolated beyond these eight countries. The third limitation is that the set of cultural capital variables account for only $5.03 \%$ of the student achievement variance. This suggests that there could be other indicators of cultural capital that are not included in the HLM models estimated. These indicators could be those pertaining to parental familiarity with institutional evaluation standards, highbrow culture, other emerging aspects of cultural capital that have not been examined, or even country-specific forms of cultural capital. Finally, social, human, and economic capital might also explain some of the student achievement variance.

Moving forward, future research could examine why parents' perceived importance of mathematics in future jobs is not as strong a predictor of student mathematics achievement as expected. In particular, researchers can investigate how these perceptions are related to parental expectations of their children, and compare the influence of these perceptions with that of other psychosocial variables on student achievement. Researchers can also examine how other variables related to parent and child habitus, economic interest, and cultural capital coalesce to influence student achievement. Another research trajectory is to compare the power of the other theoretical perspective related to elite status culture with the 'familiarity' perspective as examined in the present study in explaining student achievement. 


\section{References}

Acosta, S. \& Hsu, H. Y. (2014) Shared academic values: testing a model of the association between Hong Kong parents' and adolescents' perception of the general value of science and scientific literacy, Educational Studies, 40(2), 174-195.

Archer, L., Dawson, E., DeWitt, J., Seakins, A. \& Wong, B. (2015) 'Science capital'”: a conceptual, methodological, and empirical argument for extending Bourdieusian notions of capital beyond the arts, Journal of Research in Science Teaching, 52(7), 922-948.

Aschbacher, P. R., Ing, M. \& Tsai, S. (2013) Boosting student interest in science, Phi Delta Kappan, 95(2), 47-51.

Baker, D. P., Goesling, B. \& LeTendre, G. K. (2002) Socioeconomic status, school quality, and national economic development: a cross-national analysis of the "HeynemanLoxley Effect" on mathematics and science achievement, Comparative Education Review, 46, 291-312.

Ball, S. J. (2003) The teacher's soul and the terrors of performativity, Journal of Education Policy, 18(2), 215-228.

Boone, S. \& Van Houtte, M. (2013) In search of the mechanisms conducive to class differentials in educational choice: a mixed method research, The Sociological Review, 61, 549-572.

Bourdieu, P. (1986) The forms of capital, in: J. Richardson (Ed) Handbook of theory and research for the Sociology of Education (New York, NY, Greenwood Press).

Bourdieu, P. (1990) The logic of practice (Cambridge, UK, Polity).

Bourdieu, P. (1993) The field of cultural production: essays on art and literature (Cambridge, UK, Polity).

Bourdieu, P. (1994) In other words: essays towards a reflexive sociology (Cambridge, UK. Polity).

Bourdieu, P. (1996) The state nobility (Stanford, CA, Stanford University Press).

Bourdieu, P. (2000) Pascalian meditations (Cambridge, UK, Polity).

Bourdieu, P. (2005) The social structures of the economy (Cambridge, UK, Polity).

Bourdieu, P. \& Passeron, J.-C. (1977) Reproduction in education, society and culture (London, UK, Sage).

Bourdieu, P. \& Passeron, J. (1979) The inheritors (Chicago, IL, University of Chicago Press).

Calabrese Barton, A., Kang, H., Tan, E., O’Neill. T. B., Bautista-Guerra, J. \& Brecklin, C. (2013) Crafting a future in science: tracing middle school girls' identity work over time and space, American Educational Research Journal, 50, 3-75.

Castro, M., Expósito-Casas, E., López-Martín, E., Lizasoain, L., Navarro-Asencio, E. \& Gaviria, J. L. (2015) Parental involvement on student academic achievement: a metaanalysis, Educational Research Review, 14, 33-46.

Cheema, J. R. (2014) A review of missing data handling methods in education research, Review of Educational Research, 84(4), 487-508.

Chen, W.-B. \& Gregory, A. (2010) Parental involvement as a protective factor during the transition to high school, The Journal of Educational Research, 103, 53-62.

Chiu, M. M. \& Khoo, L. (2005) Effects of resources, inequality, and privilege bias on achievement: country, school, and student level analyses, American Educational Research Journal, 42, 575-603.

Chiu, M. M. \& McBride-Chang, C. (2010) Family and reading in 41 countries: differences across cultures and students, Scientific Studies of Reading, 14, 514-543.

Claro, M., Cabello, T., Martín, E. S. \& Nussbaum, M. (2015) Comparing marginal effects of 
DOI: $10.1002 /$ berj.3303

Chilean students' economic, social and cultural status on digital versus reading and mathematics performance, Computers \& Education, 82, 1-10.

Croll, P. (2008) Occupational choice, socio $\square$ economic status and educational attainment: a study of the occupational choices and destinations of young people in the British Household Panel Survey, Research Papers in Education, 23(3), 243-268.

Crosnoe, R \& Muller, C. (2014) Family socioeconomic status, peers, and the path to college, Social Problems, 61(4), 602-624.

Dar, Y. \& Getz, S. (2007) Learning ability, socioeconomic status, and student placement for undergraduate studies in Israel, Higher Education, 54, 41-60.

De Graaf, N. D., De Graaf, P. M. \& Kraaykamp, G. (2000) Parental cultural capital and educational attainment in the Netherlands: a refinement of the cultural capital perspective, Sociology of Education, 73, 92-111.

Dedrick, R., Ferron, J., Hess, M., Hogarty, K., Kromrey, J., Lang, T. et al. (2009) Multilevel modelling: a review of methodological issues and applications, Review of Educational Research, 79(1), 69-102.

Demerath, P., Lynch, J., Milner IV, H. R., Peters, A. \& Davidson, M. (2010) Decoding success: a middle-class logic of individual advancement in a U.S. suburb and high school, Teachers College Record, 112(12), 2935-2987.

DiMaggio, P. (1982) Cultural capital and school success: the impact of status culture participation on the grades of U.S. high school students, American Sociological Review, 47, 189-201.

Dubow, E. F., Boxer, P. \& Huesmann, L. R. (2009) Long-term effects of parents' education on children's educational and occupational success: mediation by family interactions, child aggression, and teenage aspirations, Merrill-Palmer Quarterly, 55, 224-249.

Ganzeboom, H. B. G. (2010) Questions and answers about ISEI-08. Available online at: http://www.harryganzeboom.nl/isco08/qa-isei-08.htm (accessed 15 April 2017).

Gauld, C. F. \& Hukins, A. A. (1980) Scientific attitudes: a review, Studies in Science Education, 7, 129-161.

Gniewosz, B. \& Noack, P. (2012) Mamakind or papakind? [Mom's child or Dad's child]: parent-specific patterns in early adolescents' intergenerational academic value transmission, Learning and Individual Differences, 22, 544-548.

Gordon, M. F. \& Louis, K. S. (2009) Liking parent and community involvement with student achievement: comparing principal and teacher perceptions of stakeholder influence, American Journal of Education, 116(1), 1-31.

Han, S. \& Makino, A. (2013) Learning cities in East Asia: Japan, the Republic of Korea and China, International Review of Education, 59, 443-468.

Hattie, J. (2009) Visible learning: a synthesis of over 800 meta-analyses relating to achievement (Oxon, UK \& New York, NY, Routledge).

Hanushek, E. A, \& Woessmann, L. (2017) School resources and student achievement: A review of cross-country economic research, in: M. Rosén, K. Y. Hansen, \& U. Wolff (Eds) Cognitive abilities and educational outcomes : A festschrift in honour of JanEric Gustafsson (Cham, Switzerland, Springer).

Hauser, R. M., Tsai, S.-L. \& Sewell, W. H. (1983) A model of stratification with response error in social and psychological variables, Sociology of Education, 56, 20-46.

Heyneman, S., \& Loxley, W. A. (1983) The effect of primary-school quality on academic achievement across twenty-nine high- and low-income countries, American Journal of Sociology, 88(6), 1162-1194.

Hvistendahl, R \& Roe, A. (2004) The literacy achievement of Norwegian minority students, Scandinavian Journal of Educational Research, 48, 307-324.

Iruka, I. U., Dotterer, A. M. \& Pungello, E. P. (2014) Ethnic variations of pathways linking 
DOI: $10.1002 /$ berj.3303

socioeconomic status, parenting, and preacademic skills in a nationally representative sample, Early Education and Development, 25, 973-994.

Jacobs, N. \& Harvey, D. (2005) Do parents make a difference to children's academic achievement? Differences between parents of higher and lower achieving students, Educational Studies, 31(4), 431-448.

Jaeger, M. M. (2009) Equal access but unequal outcomes: cultural capital and educational choices in a meritocratic society, Social Forces, 87(49), 1943-1972.

Krapp, A. \& Prenzel, M. (2011) Research on interest in science: theories, methods, and findings, International Journal of Science Education, 33(1), 27-50.

Ladd, H. F. \& Fiske, E. B. (2003) Does competition improve teaching and learning? Evidence from New Zealand, Educational Evaluation and Policy Analysis, 25(1), 97-112.

Lareau, A. \& Weininger, E. B. (2003) Cultural capital in educational research: a critical Assessment, Theory and Society, 32, 567-606.

Lee, M., Walker, A. \& Chui, Y. L. (2012) Contrasting effects of instructional leadership practices on student learning in a high accountability context, Journal of Educational Administration, 50(5), 586-611.

Liou, P.-Y. \& Hung, Y.-C. (2015) Statistical techniques utilized in analyzing PISA and TIMSS data in science education from 1996 to 2013: a methodological review, International Journal of Science and Mathematics Education, 13, 1449-1468.

Little, A. \& Rolleston, C. (2014) School quality counts: Evidence from developing countries, Oxford Review of Education, 40(1), 1-9.

Ma, Y. (2009) Family socioeconomic status, parental involvement, and college major choices — gender, race/ethnic, and nativity patterns, Sociological Perspectives, 52(2), 211234.

Mudiappa, M. \& Kluczniok, K. (2015) Visits to cultural learning places in the early childhood, European Early Childhood Education Research Journal, 23, 200-212.

Myrberg, E. \& Rosén, M. (2009) Direct and indirect effects of parents' education on reading achievement among third graders in Sweden, British Journal of Educational Psychology, 79, 695-711.

OECD. (2013) PISA 2012 results in focus: what 15-year-olds know and what they can do with what they know. Available online at: http://www.oecd.org/pisa/keyfindings/pisa2012-results-overview.pdf (accessed 15 April 17).

OECD. (2014) PISA 2012 technical report. Available online at: http://www.oecd.org/pisa/pisaproducts/PISA-2012-technical-report-final.pdf (accessed 15 April 17).

OECD. (2015) Universal basic skills: what countries stand to gain. Available online at: https://www.oecd.org/edu/universal-basic-skills-9789264234833-en.htm (accessed 15 April 17)

Osborne, J., Simon, S. \& Collins, S. (2003) Attitudes towards science: a review of the literature and its implications, International Journal of Science Education, 25(9), 1049-1079.

Perera, J. D. H. (2014) Parents' attitudes towards science and their children's science achievement, International Journal of Science Education, 36(18), 3021-3041.

Prieur, A. \& Savage, M. (2013) Emerging forms of cultural capital, European Societies, 15(2), 246-267.

Raudenbush, S. \& Bryk, A. (2002) Hierarchical linear models: applications and data analysis methods ( $2^{\text {nd }}$ ed.) (Thousand Oaks, CA, Sage).

Raudenbush, S., Bryk, A., Cheong, Y. F., Congdon, R. \& du Tolt, M. (2011) HLM7: hierarchical linear and nonlinear modeling (Lincolnwood, IL, Scientific Software International). 
DOI: $10.1002 /$ berj.3303

Reay, D. (2004) Education and cultural capital: the implications of changing trends in education policies, Cultural Trends, 13(2), 73-86.

Rimkute, L., Hirvonen, R., Tolvanen, A., Aunola, K. \& Nurmi, J. E. (2012) Parents' role in adolescents' educational expectations, Scandinavian Journal of Educational Research, $56,571-590$.

Sektnan, M., McClelland, M. M., Acock, A. \& Morrison, F. J. (2010) Relations between early family risk, children's behavioral regulation, and academic achievement, Early Childhood Research Quarterly, 25, 464-479.

Sirin, S. R. (2005) Socioeconomic status and academic achievement: a meta-analytic review of research, Review of Educational Research, 75, 417-453.

Sullivan, A. (2001) Cultural capital and educational attainment, Sociology, 35, 893-912.

Tan, C. Y. (2015) The contribution of cultural capital to students' mathematics achievement in medium and high socioeconomic gradient economies, British Educational Research Journal, 41(6), 1050-1067.

Tan, C. Y. (2017) Conceptual diversity, moderators, and theoretical issues in quantitative studies of cultural capital theory, Educational Review, DOI: 10.1080/00131911.2017.1288085

Vryonides, M. (2007) Social and cultural capital in educational research: issues of operationalisation and measurement, British Educational Research Journal, 33, 867885.

Weininger, E. B. \& Lareau, A. (2003) Translating Bourdieu into the American context: the question of social class and family-school relations, Poetics, 31, 375-402.

Wu, M. (2005) The role of plausible values in large-scale surveys, Studies in Educational Evaluation, 31, 114-128.

Xie, Y., Fang, M. \& Shauman, K. (2015) STEM education, Annual Review of Sociology, 41, 331-57.

Young, W., Weckman, G. \& Holland, W. (2011) A survey of methodologies for the treatment of missing values within datasets: limitations and benefits, Theoretical Issues in Ergonomics Science, 12, 15-43.

Zadeh, Z. Y., Farnia, F. \& Ungerleider, C. (2010) How home enrichment mediates the relationship between maternal education and children's achievement in reading and math, Early Education and Development, 21, 568-594. 